\title{
Carnosic Acid Inhibits Lipid Accumulation in 3T3-L1 Adipocytes Through Attenuation of Fatty Acid Desaturation
}

\author{
Mi-Young Park', Mi-Kyung Sung ${ }^{2}$ \\ ${ }^{1}$ Department of Food and Nutrition Education, Graduate School of Education, Soonchunhyang University, Asan, ${ }^{2}$ Department of Food and Nutrition, \\ College of Human Ecology, Sookmyung Women's University, Seoul, Korea
}

\begin{abstract}
Background: Excess body fat accumulation contributes to the development of metabolic disorders that can cause adverse health effects. Carnosic acid (CA), a major bioactive component of rosemary (Rosemarinus officinalis), has been suggested to possess anti-adipogenic properties. The present study was conducted to elucidate the mechanism underlying the anti-adipogenic effects of CA.

Methods: 3T3-L1 pre-adipocytes were treated with CA $(0.1,1$, and $10 \mu \mathrm{M})$ from day 0 to day 8 of differentiation. On day 8 , biochemical markers of lipid accumulation and the degree of fatty acid desaturation were measured.

Results: Oil Red 0 staining results, triglyceride (TG) accumulation, and glycerol 3-phosphate dehydrogenase activity suggested that CA significantly inhibited lipid accumulation in 3T3-L1 adipocytes. CA significantly decreased mRNA expression of peroxisome proliferatoractivated receptor- $\gamma$, sterol regulatory element-binding protein 1, and CCAAT/enhancer binding protein- $\alpha$ in a dose-dependent manner.

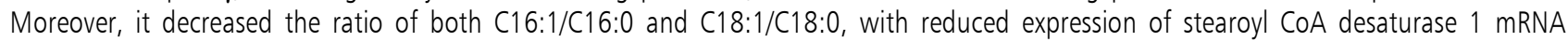
and protein.

Conclusions: These results suggest that CA efficiently suppressed adipogenesis in 3T3-L1 adipocytes and its action, at least in part, is associated with the downregulation of adipogenesis-related genes and the fatty acid composition of TG accumulated in adipocytes. (J Cancer Prev 2015;20:41-49)
\end{abstract}

Key Words: 3T3-L1 adipocytes, Carnosic acid, Differentiation, Fatty acid

\section{INTRODUCTION}

Obesity is characterized by excess accumulation of fat in the adipose tissue. Adipocytes are highly specialized cells that play a critical role in maintaining cellular energy homeostasis by storing excess energy as triglycerides (TG). However, it has been well documented that enlarged adipocytes contribute to dysregulation of lipid metabolism, thereby contributing to insulin resistance and chronic inflammation. ${ }^{1-3}$ Therefore, obesity-associated metabolic disorders may be prevented by decreasing the number of adipocytes and by suppressing lipid accumulation within adipocytes. Peroxisome proliferator-activated receptor- $\gamma$ (PPAR $\gamma$ ), sterol regulatory element-binding protein1 (SREBP1), and CCAAT/ enhancer binding protein- $\alpha(\mathrm{C} / \mathrm{EBP} \alpha)$ are key transcriptional factors involved in lipid accumulation in differentiating 3T3-L1 adipocytes. These genes promote the expression of adipogenesisrelated genes. ${ }^{4}$

Recent studies have suggested that increased desaturation of stearate is also associated with adipogenesis. In obese humans, stearoyl-CoA desaturase 1 (SCD1), which catalyzes the conversion of palmitate (C16:0) and stearate $(\mathrm{C} 18: 0)$ to palmitoleate $(\mathrm{C} 16: 1)$ and oleate (C18:1), respectively, is shown to be upregulated. ${ }^{5}$ In mice, adipose-specific deletion of SCD1 induced upregulation of GLUT1, which plays a critical role in glucose utilization. ${ }^{6}$ Moreover, high ratios of monounsaturated to saturated fatty acids (SFA) (C16:1/C16:0 and 18:1/C18:0) in adipose tissue TG have been used as an index of obesity-related hyperlipidemia. ${ }^{7}$ Adipose tissue stearic acid (C18:0) content was positively related

Received December 30, 2014, Revised February 27, 2015, Accepted February 27, 2015

Correspondence to: Mi-Kyung Sung

Department of Food and Nutrition, College of Human Ecology, Sookmyung Women's University, 100 Cheongpa-ro 47-gil, Yongsan-gu, Seoul 140-742, Korea Tel: +82-2-710-9395, Fax: +82-2-710-9453, E-mail: mksung@sm.ac.kr, ORCID: Mi-Kyung Sung, http://orcid.org/0000-0002-3575-5628

Copyright (C) 2015 Korean Society of Cancer Prevention

(c) This is an Open Access article distributed under the terms of the Creative Commons Attribution Non-Commercial License (http://creativecommons. org/icenses/by-nc/3.0) which permits unrestricted non-commercial use, distribution, and reproduction in any medium, provided the original work is properly cited. 
to insulin sensitivity, but negatively associated with adipoctye size. ${ }^{8}$ These findings suggest that increased adipocyte desaturation indexes (C16:1/C16:0 and C18:1/C18:0) may be closely related to lipid accumulation in adipocytes and obesity-related metabolic complications.

Carnosic acid (CA) is a major phenolic compound of rosemary (Rosemarinus officinalis L.) leaves. A previous study indicated that CA inhibited mouse 3T3-L1 adipocyte differentiation and hepatic TG accumulation in ob/obmice; ${ }^{9}$ however, the molecular mechanisms underlying these effects have not been explored. In a previous study, a $0.02 \%$ CA diet significantly decreased the hepatic content of oleic acid (C18:1), in an animal model of high-fat diet-induced hepatic steatosis. ${ }^{10}$ In this study, we examined the effect of CA on lipid accumulation in differentiating 3T3-L1 adipocytes. Additionally, the molecular mechanisms involved in the regulation of lipid accumulation were investigated with special emphasis on the ratio between C16:1/ $\mathrm{C} 16: 0$ and C18:1/C18:0 as an important regulatory factor of lipid accumulation.

\section{MATERIALS AND METHODS}

\section{Materials}

CA was obtained from GBLS Corporation Ltd. (Hwasung, Korea). Dulbecco's modified Eagle's medium (DMEM), bovine calf serum (BCS), antibiotics-antimycotics solution, and trypsin-ethylenediaminetetraacetic acid (EDTA) were purchased from GIBCO Co. (Grand Island, NY, USA). Dexamethasone (DEX), 3-isobutyl-1methylxanthine (IBMX), insulin, and Oil Red O were purchased from Sigma-Aldrich (St. Louis, Mo, USA). Fatty acid methyl ester (FAME) standards were purchased from Supelco (Bellefonte, PA, USA). All solvents and reagents used were of analytical grade. Boron trifluoride methanol solution $\left(14 \% \mathrm{BF}_{3}\right)$, sodium hydroxide, and sodium chloride were purchased from Sigma-Aldrich. Chloroform, normal hexane, and methanol were purchased from J. T. Baker (Philipsburg, NJ, USA).

\section{3T3-L1 cell differentiation}

Mouse 3T3-L1 fibroblast cells, obtained from Korean Cell Line Bank (KCLB, Seoul, Korea), were cultured in six-well tissue culture plates. The cells were maintained in DMEM supplemented with $10 \%$ heat-inactivated BCS, 100 units/mL penicillin, and $100 \mu \mathrm{g} / \mathrm{mL}$ streptomycin. One day after confluency (designated as day 0), cell differentiation was induced by adipogenic agents (0.5 mM IBMX, $2 \mu \mathrm{M}$ DEX, and 0.7 $\mu \mathrm{M}$ insulin), which were added to the culture medium. CA $(0.1,1$, and $10 \mu \mathrm{M})$ was added to the culture medium at the initiation of differentiation and with every subsequent medium change for 8 days.

\section{Cell viability (MTT assay)}

After the indicated treatment, cells were washed with PBS once, the cells were incubated with $5 \mathrm{mg} / \mathrm{mL}$ 3-(4,5-dimethylthiazol2-yl)-2,5-diphenyltetrazolium bromide (MTT) solution for 4 hours at $37^{\circ} \mathrm{C}$. The purple formazan crystals were then dissolved with dimethyl sulfoxide (DMSO). After incubation for 15 minutes, absorbance was measured at $540 \mathrm{~nm}$ using a microplate reader (Molecular Devices, CA, USA).

\section{Oil Red O staining}

After 8 days of adipogenic differentiation from the point of confluency (day 0), cultured preadipocytes were fixed with 3.7\% formalin for 1 hour, and stained with Oil Red O (three parts $0.5 \%$ Oil Red O dye in isopropanol to two parts water) for 40 minutes. The stained cells were washed three times with water. Oil Red O was then eluted with DMSO and quantified by measuring the optical density (OD) at $490 \mathrm{~nm}$.

\section{Triglyceride accumulation}

3T3-L1 adipocytes were harvested 8 days after the initiation of differentiation. The cells were washed twice with cold phosphatebuffered saline (PBS), collected, and lysed in lysis buffer (1\% Triton X-100 in PBS). The total TG content in the cells was determined using a TG kit (Wako Chemical, Osaka, Japan). The protein concentration was determined using BioRed DC protein assay kit (Bio-Rad Laboratories, Hercules, CA, USA). Inhibition was expressed as the percentage (\%) decrease in TG content against a control (0\%).

\section{Glycerol 3-phosphate dehydrogenase activity}

3T3-L1 adipocytes were harvested 8 days after the initiation of differentiation. The cells were washed twice with cold PBS, scraped into $200 \mu \mathrm{L}$ of an enzyme extract buffer (provided with the kit), and sonicated. Glycerol 3-phosphate dehydrogenase (GPDH) activity was determined using a GPDH kit (Takara Bio, Shiga, Japan) according to the manufacturer's protocol.

\section{RNA extraction and real-time polymerase chain reaction}

Total RNA was isolated from the 3T3-L1 cells using Trizol reagent (Invitrogen, Carlsbad, CA, USA) following the manufacture's recommendations. Real-time quantitative polymerase chain reaction (PCR) was performed with an SYBR Green ${ }^{\mathrm{TM}}$ kit 
(Quantitect ${ }^{\mathrm{TM}}$ SYBR Green PCR; QIAGEN, Valencia, CA, USA). The cycling conditions were 15 minutes at $95^{\circ} \mathrm{C}, 40$ cycles of 15 seconds at $94^{\circ} \mathrm{C}, 30$ seconds at $51^{\circ} \mathrm{C}$, and 30 seconds at $72^{\circ} \mathrm{C}$. Relative quantification was performed using the Delta-Delta method. ${ }^{11}$ The primer sequences of the genes examined are shown in Table 1.

\section{Fatty acid analyses}

Cellular lipids were extracted using a previously reported procedure. ${ }^{12}$ The fatty acid composition of adipocytes was analyzed according to the method described by Kramer et al. ${ }^{13}$ The methyl ester of total fatty acid was obtained using the reaction in a Techne DB-3D heating block (Barloworld Scientific US Ltd., Burlington, NJ, USA), with BF3 as a catalyst. FAMEs were determined using a gas chromatograph (Agilent 6890N GC; Agilent Technologies, Santa Clara, CA, USA) equipped with a flame ionization detector (FID) and an HP-FFAP capillary column (30 m $\times 0.32 \mathrm{~mm} \times 0.25 \mu \mathrm{M}$ film thickness; Agilent Technologies). The injector temperature was $230^{\circ} \mathrm{C}$ with a split ratio of $10: 1$ and the FID temperature was $250^{\circ} \mathrm{C}$. The oven temperature program involved $100^{\circ} \mathrm{C}$ for 1 minute, $100^{\circ} \mathrm{C}$ to $230^{\circ} \mathrm{C}$ at a rate of $3^{\circ} \mathrm{C}$ per minute, and $230^{\circ} \mathrm{C}$ for 10 minutes. Helium was used as the carrier gas with a constant flow rate of 1.0 $\mathrm{mL} / \mathrm{min}$ and the injection volume was $1 \mu \mathrm{L}$. Hydrogen flow to the detector was $40 \mathrm{~mL} / \mathrm{min}$, the air flow was $300 \mathrm{~mL} / \mathrm{min}$, and the helium make-up gas flow rate was $20 \mathrm{~mL} / \mathrm{min}$.

\section{Western blotting}

For the detection of SCD1, the total protein from the 3T3-L1 cells was extracted using a protein extraction buffer $(50 \mathrm{mM} \mathrm{NaF}$, $50 \mathrm{mM}$ Tris $\mathrm{HCl}, 5 \mathrm{mM} \mathrm{NaPPi}, 150 \mathrm{mM} \mathrm{NaCl}, 1 \% \mathrm{NP}-40,1 \mathrm{mM}$

Table 1. Gene-specific primers used for real-time polymerase chain reaction

\begin{tabular}{cll}
\hline Gene & Direction & \multicolumn{1}{c}{ Sequence } \\
\hline PPAR $\gamma$ & Forward & 5'-TTT TCA AGG GTG CCA GTT TC-3' \\
& Reverse & 5'-AAT CCT TGG CCC TCT GAG AT-3' \\
SREBP1 & Forward & 5'-TGT TGG CAT CCT GCT ATC TG-3' \\
& Reverse & 5'-AGG GAA AGC TTT GGG GTC TA-3' \\
C/EBPQ & Forward & 5'-TTA CAA CAG GCC AGG TTT CC-3' \\
& Reverse & 5'-GGC TGG CGA CAT ACA GTA CA-3' \\
SCD1 & Forward & 5'-GGA TCA GGT TTT GTG GTG CT-3' \\
& Reverse & 5'-TTG TGG CCC ATA AAG TCC TC-3' \\
$\beta$ 3-Actin & Forward & 5'-CCA CAG CTG AGA GGG AAA TC-3' \\
& Reverse & 5'-AAG GAA GGC TGG AAA AGA GC-3'
\end{tabular}

PPAR $\gamma$, peroxisome proliferator-activated receptor- $\gamma ;$ SREBP1, sterol regulatory element-binding protein 1; C/EBP $\alpha$, CCAAT/enhancer binding protein- $\alpha$; SCD1, stearoyl $\mathrm{CoA}$ desaturase 1 .
Na3VO4, and $1 \mathrm{mM}$ EDTA). For each sample, $40 \mu \mathrm{g}$ of protein was denatured in Laemmli Buffer for 5 minutes at $95^{\circ} \mathrm{C}$. Proteins were separated by sodium dodecyl sulfate-polyacrylamide gel electrophoresis and transferred to polyvinylidene difluoride membranes. After blocking with a blocking buffer (5\% skim milk in PBS), the membranes were incubated with the SCD1 antibody (Cell Signaling Technology, Inc, Danvers, MA, USA). The proteins were visualized using enhanced chemiluminescence with horseradish peroxidase-conjugated anti-rabbit immunoglobulin $\mathrm{G}$. Blots were scanned and analyzed using a multiple image analyzer and the Quantity One program (Bio-Rad Laboratories).

\section{Statistical analysis}

Statistical analysis was performed using the SAS package release 9.3 (SAS Institute Inc., Cary, NC, USA). Data were expressed as means \pm standard deviation. Data were analyzed using one-way analysis of variance followed by Duncan's multiple range tests. A $P$-value of $<0.05$ was considered statistically significant.

\section{RESULTS}

\section{Effects of carnosic acid on 3T3-L1 adipocytes viability}

3T3-L1 adipocytes viability was assessed by MTT assay. As shown Table 2, CA in the concentrations used did not affect viability of 3T3-L1 cells.

\section{Effects of carnosic acid on lipid accumulation and glycerol 3-phosphate dehydrogenase activity in 3T3-L1 adipocytes}

The effects of CA on the accumulation of intracellular lipid droplets in 3T3-L1 adipocytes are shown in Figure 1. Compared to the OD value of control cells, the OD values of Oil Red O in the cells treated with $1 \mu \mathrm{M}$ and $10 \mu \mathrm{M}$ CA significantly decreased by $19.1 \%$ and $33.4 \%$, respectively, indicating reduced intracellular lipid accumulation ( $P<0.05$; Fig. 1B). Cellular TG was quantified, and adipocytes treated with $\mathrm{CA}$ at $1 \mu \mathrm{M}$ and $10 \mu \mathrm{M}$ showed

Table 2. Effect of carnosic acid on 3T3-L1 viability

\begin{tabular}{cc}
\hline Carnosic acid $(\mathrm{mM})$ & Viability $(\%$ control) \\
\hline 0 & 100 \\
0.1 & $98.7 \pm 3.8$ \\
1.0 & $96.4 \pm 8.9$ \\
10.0 & $95.9 \pm 4.2$ \\
\hline
\end{tabular}

Values are presented as number only or mean \pm SD. 
A
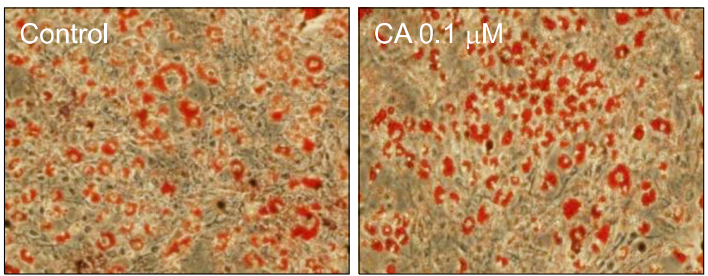

CA $1 \mathrm{M}^{2}$
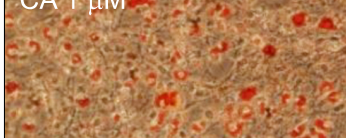

(.)

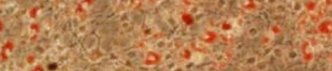

C
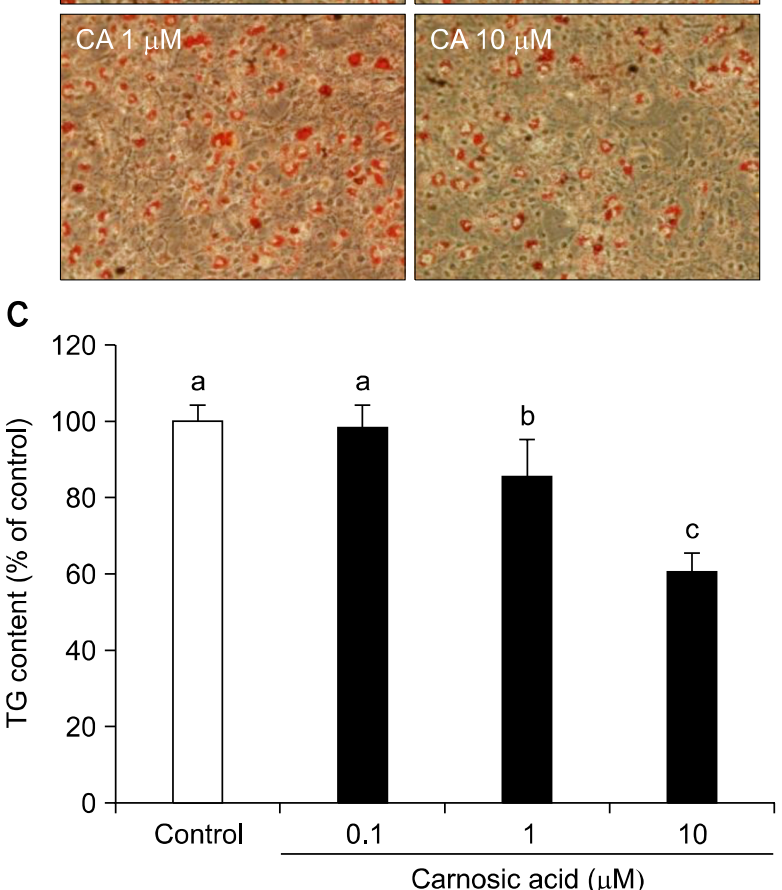

B

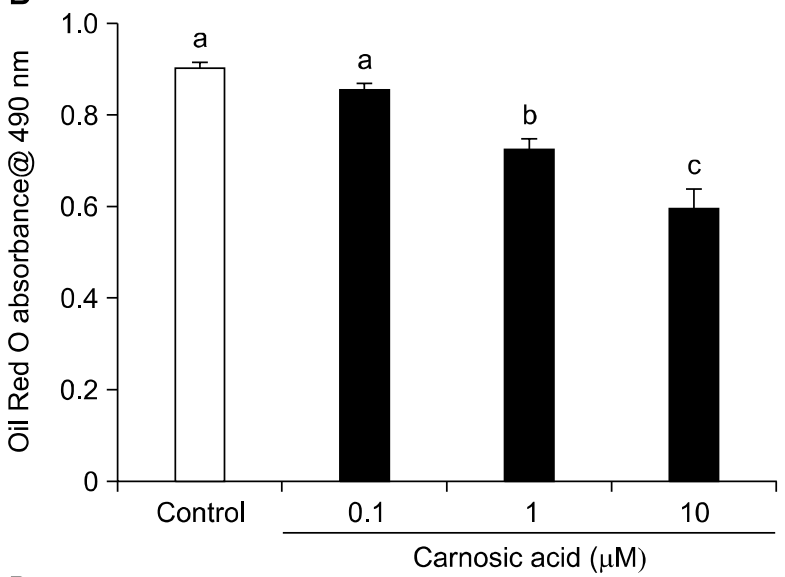

D

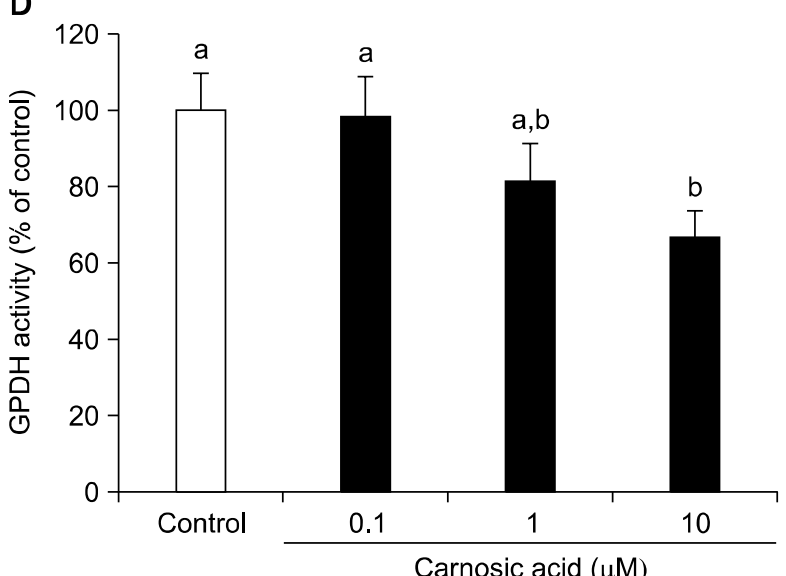

Figure 1. Effects of carnosic acid (CA) on adipocyte differentiation, triglyceride (TG) content, and glycerol 3-phosphate dehydrogenase (GPDH) activity in 3T3-L1 cells. Preadipocytes were grown to confluency (day 0) and induced to differentiate with an optimized adipocyte differentiation medium in the presence of CA $(0.1,1$, and $10 \mu \mathrm{M})$ throughout differentiation. (A) Morphological observation and Oil Red $O$ staining of 3T3-L1 cells. After differentiation (day 8), the cells were fixed and stained with Oil Red $O$ and photographed using a microscope ( $\times$ 200). (B) Quantification of intracellular Oil Red O staining using spectrophotometry. (C) Quantification of TG content in 3T3-L1 cells. (D) GPDH activity in 3T3-L1 cells. Data are expressed as mean \pm standard deviation $(\mathrm{n}=4)$. ${ }^{\text {a.b.c }}$ Means with the different letters are significantly different from each other $(P<0.05)$ using Duncan's multiple-range test.

reduced TG content by $15.5 \%$ and $39.8 \%$, respectively, compared to that in the control cells $(P<0.05$; Fig. 1C). The activity of cytosolic GPDH, a key regulatory enzyme involved in TG synthesis was also significantly decreased in CA-treated adipocytes compared to that in the control cells $(P<0.05$; Fig. 1D).

\section{Effect of carnosic acid on adipogenesis-related gene expression in 3T3-L1 adipocytes}

To gain a better understanding of the molecular mechanism(s) underlying the anti-adipogenic effects of $\mathrm{CA}$, we examined the expression levels of key transcriptional factors. Consistent with the decreases in TG accumulation and GPDH activity, CA significantly decreased the mRNA expression of PPAR $\gamma$, C/EBP $\alpha$, and SREBP1 in a dose-dependent manner. Treatment with $10 \mu \mathrm{M}$
CA significantly decreased the mRNA expression of PPAR $\gamma$, C/EBP $\alpha$, and SREBP1 by $63.54 \%, 51.05 \%$, and $47.91 \%$, respectively, compared to the corresponding values in the control cells $(P<$ 0.05; Fig. 2).

\section{Effect of carnosic acid on the ratio of monoun- saturated fatty acids to saturated fatty acids in 3T3-L1 adipocytes}

Adipocytes treated with 1 and $10 \mu \mathrm{M}$ CA had a significantly lower monounsaturated fatty acids (MUFA) to SFA ratio compared to that in the control cells. Treatment with $10 \mu \mathrm{M}$ CA significantly decreased the ratios of $\mathrm{C} 16: 1 / \mathrm{C} 16: 0$ and $\mathrm{C} 18: 1 / \mathrm{C} 18: 0$ by $42.86 \%$ and $41.25 \%$ of the control cells, respectively $(P<0.05$; Fig. 3$)$. 
A

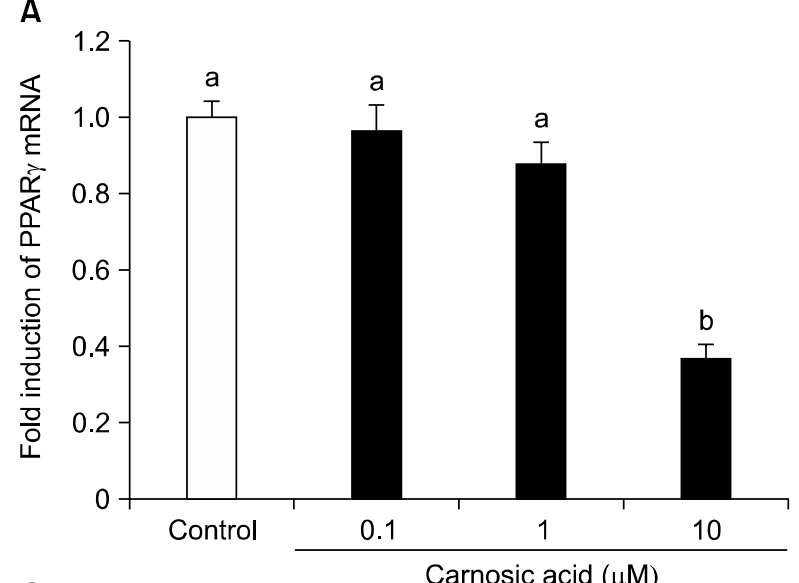

C

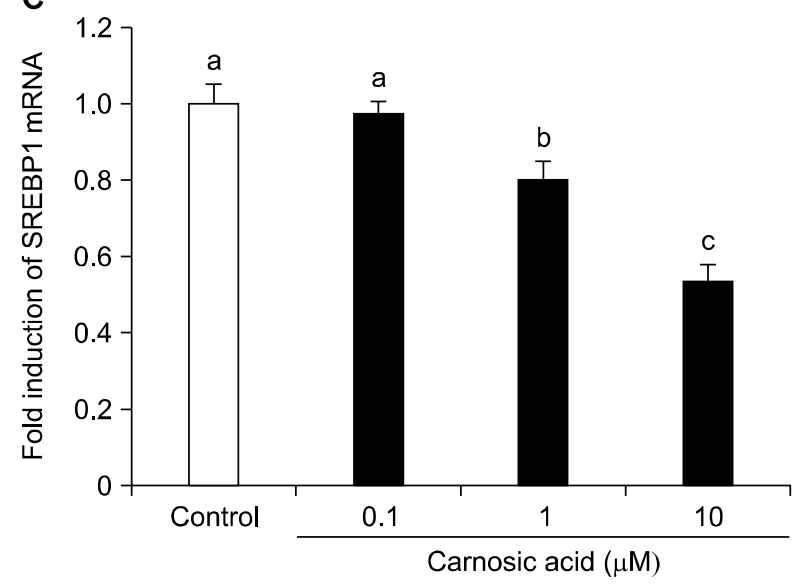

A

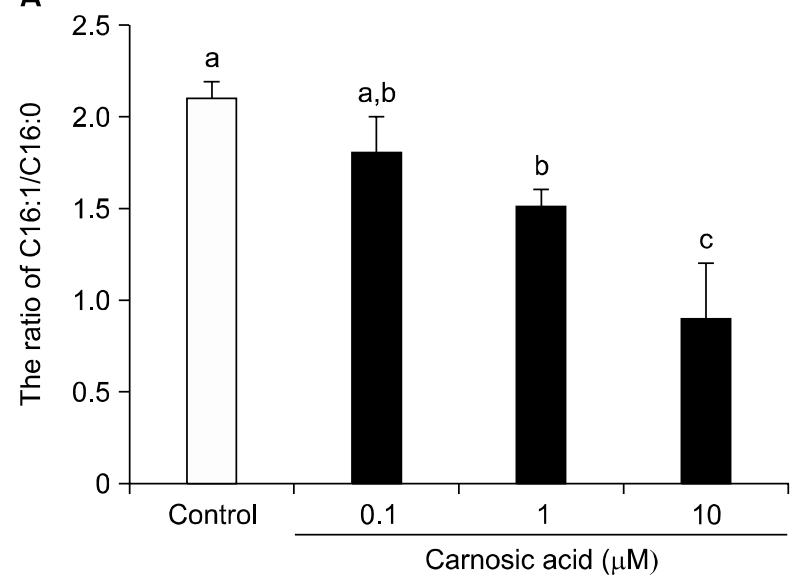

B

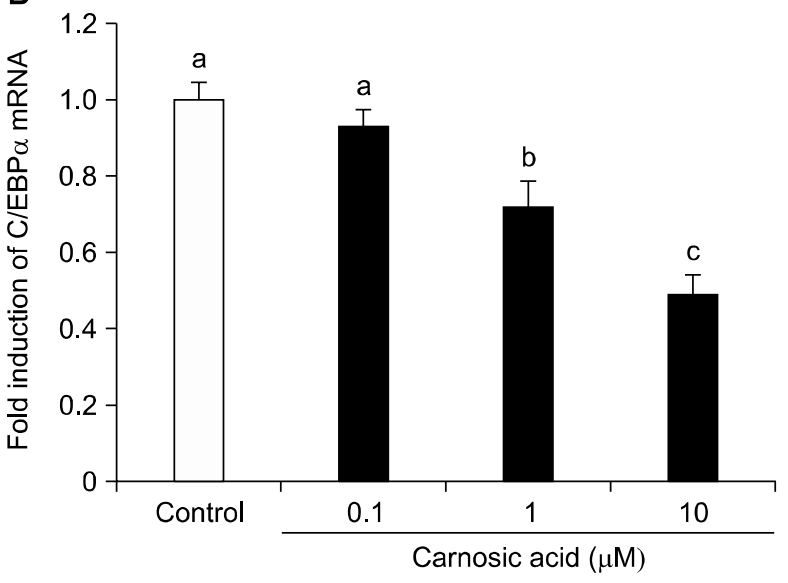

Figure 2. Effect of carnosic acid (CA) on mRNA expression levels of peroxisome proliferator-activated receptor- $\gamma(\operatorname{PPAR} \gamma)(\mathrm{A}), \mathrm{CCAAT} /$ enhancer binding protein- $\alpha(\mathrm{C} / \mathrm{EBP} \alpha)(\mathrm{B})$, and sterol regulatory element-binding protein 1 (SREBP1) (C) in 3T3-L1 adipocytes. Preadipocytes were grown to confluency (day 0 ) and induced to differentiate with an optimized adipocyte differentiation medium in the presence of $\mathrm{CA}(0.1,1$, and $10 \mu \mathrm{M})$ throughout differentiation. After differentiation (day 8), real-time polymerase chain reaction (RT-PCR) was performed using specific primer pairs for PPAR $\gamma$, $\mathrm{C} / \mathrm{EBP} \alpha$, and SREBP1. The relative RT-PCR values were corrected to $\beta$-actin expression levels and normalized with respect to the control. Data are expressed as mean \pm standard deviation $(n=4)$. a.b.c Means with the different letters at each sample are significantly different from each other $(P<0.05)$ using Duncan's multiple-range test.

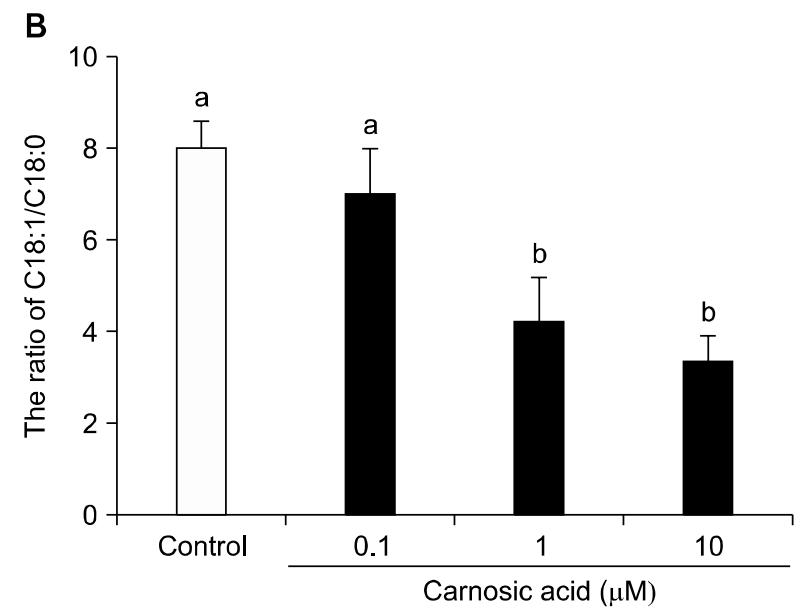

Figure 3. Effect of carnosic acid (CA) on the ratio of palmitoleate : palmitate (C16:1/C16:0) (A) and oleate : stearate (C18:1/C18:0) (B) in 3T3-L1 adipocytes. Preadipocytes were grown to confluency (day 0) and induced to differentiate with an optimized adipocyte differentiation medium in the presence of CA $(0.1,1$, and $10 \mu \mathrm{M})$ throughout differentiation. After differentiation (day 8), cellular lipids were extracted and the fatty acid composition was analyzed using gas chromatography. Data are expressed as mean \pm standard deviation $(\mathrm{n}=4)$. ${ }^{\text {a.b. } \mathrm{c}}$ Means with the different letters at each sample are significantly different from each other $(P<0.05)$ using Duncan's multiple-range test. 


\section{Effect of carnosic acid on the mRNA and protein levels of stearoyl-CoA desaturase 1 in 3T3-L1 adipocytes}

We measured the mRNA and protein levels of SCD1, which converts SFA to MUFA. As shown in Figure 4, CA led to a reduction of both the mRNA and protein expression levels of SCD1, suggesting that the decreased MUFA/SFA ratio is partly mediated through decreased SCD1 expression.

\section{DISCUSSION}

CA is a major biologically active component of rosemary and several studies have examined its biological activities including the anti-obesity, anti-inflammatory, anti-cancer, anti-viral, antioxidant properties. ${ }^{1417}$ Rosemary extract has also been shown to suppress weight gain and hepatic TG accumulation in mice fed a high-fat diet. ${ }^{18}$ The observed weight reduction by a CA-enriched rosemary extract is mediated by the suppression of gastric lipase and alteration of gut microbiota composition. ${ }^{14,19}$ Anti-adipogenic effect of $\mathrm{CA}$ is also known to be due to stimulation of glutathione metabolism in 3T3-L1 adipocytes. ${ }^{20}$ However, current evidence is insufficient to fully explain the anti-adipogenic activity of CA.

\section{A}

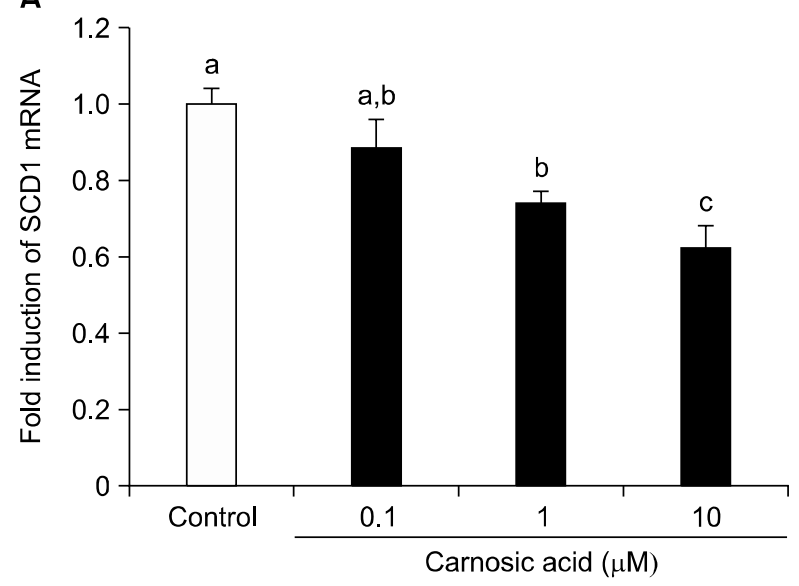

In this study, CA was found to suppress lipid accumulation in differentiating 3T3-L1 adipocytes. Oil Red O staining and cellular TG content are regarded as primary indicators of lipid accumulation in differentiating or differentiated adipocytes. Several glycerolipid-synthesizing lipogenic enzymes are highly induced during the differentiation process of 3T3-L1 preadipocytes to adipocytes. GPDH is an enzyme that catalyzes the conversion of dihydroxyacetone phosphate to sn-glycerol 3-phosphate, which is a backbone of TG and its activity is often used as a late marker of preadipocyte differentiation. ${ }^{21}$ We found that $\mathrm{CA}$ significantly inhibited GPDH activity, which indicates that CA possibly suppresses adipocyte differentiation, resulting in a reduction in the number of fat cells.

To gain a better understanding of the molecular mechanism(s) underlying its inhibitory effects on adipocyte lipid accumulation, we examined the effect of $\mathrm{CA}$ on the expression of major transcription factors of the adipogenesis pathway. During adipocyte differentiation, the accumulation of lipids is regulated by a complex network of various transcription factors and adipocyte-specific genes. In particular, PPAR $\gamma$ and C/EBP $\alpha$ act as master regulators that control the growth arrest of preadipocyte proliferation and induce differentiation and adipogenesis by regulating a large number of adipocyte-specific genes. ${ }^{22.23}$ SREBP1
B

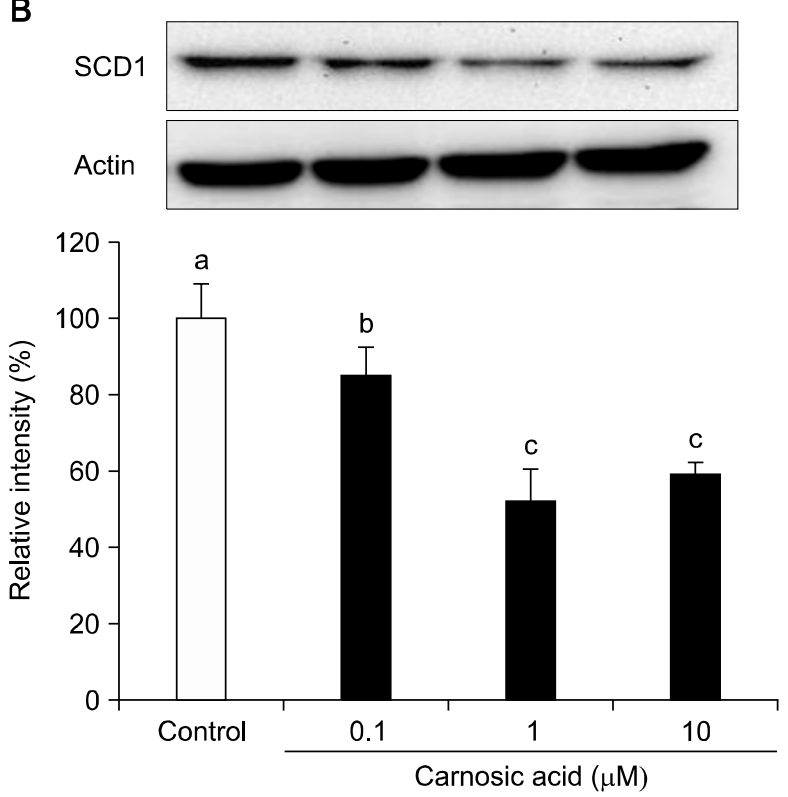

Figure 4. Effect of carnosic acid (CA) on the mRNA and protein expression levels of stearoyl CoA desaturase 1 (SCD1) in 3T3-L1 adipocytes. Preadipocytes were grown to confluency (day 0 ) and induced to differentiate with an optimized adipocyte differentiation medium in the presence of CA $(0.1,1$, and $10 \mu \mathrm{M})$ throughout differentiation. After differentiation (day 8), whole cell lysates were prepared and analyzed by immunoblotting using antibody-recognizing SCD1, and real-time polymerase chain reaction (RT-PCR) was performed using specific primer pairs for SCD1. The relative protein and RT-PCR values were corrected to $\beta$-actin expression levels and normalized with respect to the control. Data are expressed as mean \pm standard deviation $(n=4)$. ${ }^{\mathrm{a}, \mathrm{b}, \mathrm{c}}$ Means with the different letters at each sample are significantly different from each other $(P<0.05)$ using Duncan's multiple-range test. 


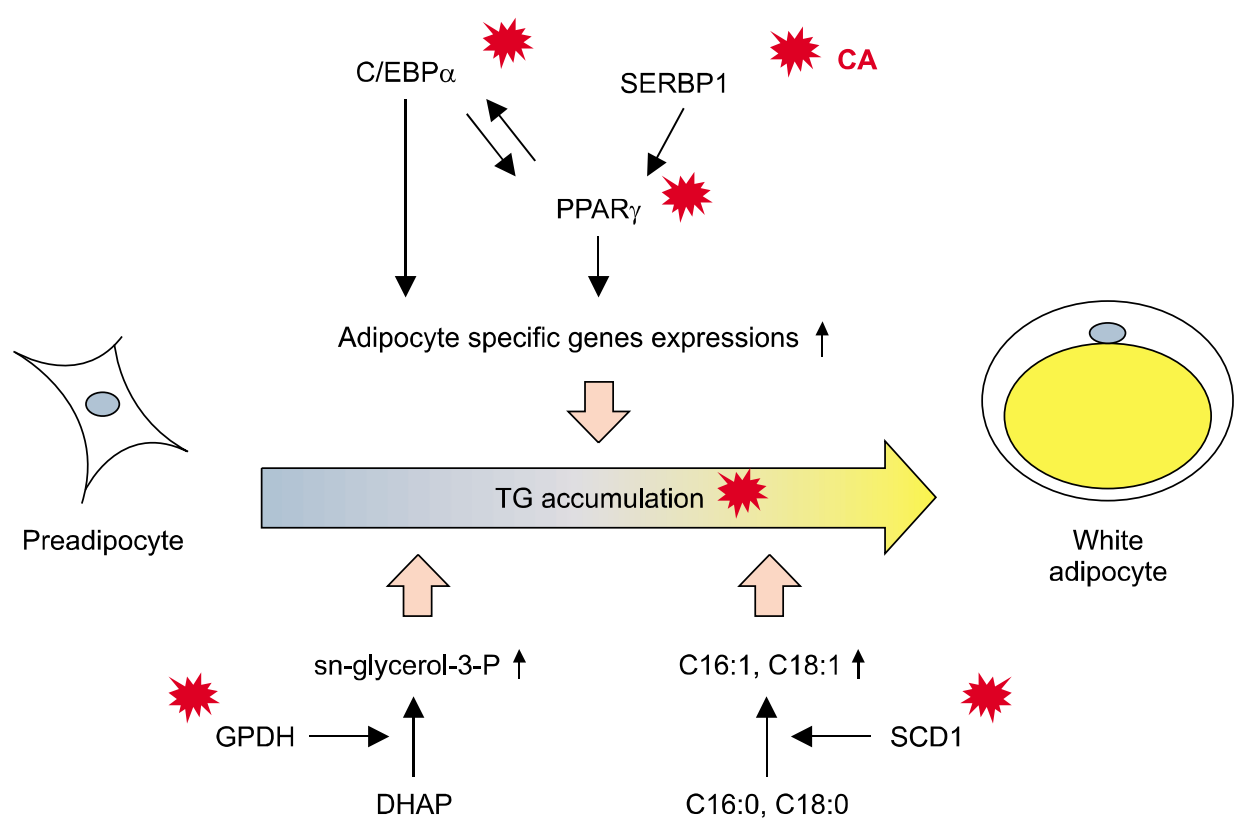

Figure 5. The hypothetical scheme of a mechanism in which carnosic acid (CA) inhibits lipid accumulation in 3T3-L1 adipocytes. CA effectively inhibits lipid accumulation in differentiating 3T3-L1 adipocytes by blocking adipocyte-associated gene expression and glycerol 3-phosphate dehydrogenase (GPDH) activity, leading to changes in fatty acid composition. PPAR $\gamma$, peroxisome proliferator-activated receptor- $\gamma$; C/EBP $\alpha$, CCAAT/enhancer binding protein- $\alpha$; SREBP1, sterol regulatory element-binding protein 1; TG, triglycerides; SCD1, stearoyl CoA desaturase 1; DHAP, dihydroxyacetone phosphate; C16:1, palmitoleate; C18:1, oleate. regulates lipid homeostasis by controlling genes associated with fatty acid synthesis and its over expression contributes to the generation of PPAR $\gamma$ ligands. ${ }^{23}$ In this study, mRNA expression of PPAR $\gamma, \mathrm{C} / \mathrm{EBP} \alpha$, and SREBP1 was reduced by CA treatment, suggesting that $\mathrm{CA}$ inhibits lipid accumulation through PPAR $\gamma$, SREBP1, and C/EBP $\alpha$ mediated-adipogenesis. Although the underlying mechanisms involved in anti-adipogenic activity of $\mathrm{CA}$ is not fully understood, studies have suggested that $\mathrm{CA}$ increased the ratio of the C/EBP $\beta$ LIP/LAP which interfere with the production of PPAR $\gamma$ agonist in 3T3-L1 cells and CA decreased both the protein expression and activity of hepatic PPAR $\gamma$ by the activation of the epidermal growth factor receptor/ mitogenactivated protein kinase (EGFR/MAPK) cascade which can inhibit lipid accumulation in hepatocytes. ${ }^{24,25}$ In our previous study, CA also effectively inhibited the expression of tumor necrosis factor- $\alpha$ (TNF- $\alpha$ ), interleukin-6 (IL-6), and monocyte chemoattractant protein-1 (MCP-1) in lipopolysaccharide-stimulated 3T3-L1 adipocytes. ${ }^{26}$ These results suggest that CA may exert anti-adipogenic effects through multiple mechanistic routes and attenuates the inflammatory response in adipocytes.

The size of the lipid droplets in an adipocyte is influenced by its fatty acid composition, which is partly regulated by SCD $1{ }^{27}$ SCD1, a PPAR $\gamma$-dependent enzyme, converts saturated palmitate (C16:0) and stearate ( $\mathrm{C} 18: 0)$ to their monounsaturated forms palmitoleate (C16:1) and oleate (C18:1), respectively. Several studies have shown that SCD1 is upregulated in obese human and animal models. ${ }^{828.29}$ Since MUFA are the major substrates for the synthesis of TGs and cellular membrane phospholipids in adipocytes, an increased ratio of monounsaturated to SFA (C16:1/ $\mathrm{C} 16: 0$ and $\mathrm{C} 18: 1 / \mathrm{C} 18: 0)$ and an increased SCD1 level indicates increased de novo lipogenesis. In humans, a lower desaturation index ( $\mathrm{C} 16: 1 / \mathrm{C} 16: 0$ and $\mathrm{C} 18: 1 / \mathrm{C} 18: 0)$ is related to lower body mass index and reduced subcutaneous adipocyte cell size, and is used as a negative predictor of metabolic syndrome. ${ }^{30}$ In the present study, $\mathrm{CA}(1$ and $10 \mu \mathrm{M})$ significantly decreased the ratio of both $\mathrm{C} 16: 1 / \mathrm{C} 16: 0$ and $\mathrm{C18}$ :1/C18:0 (Fig. 3), which was possibly accompanied by the down-regulation of SCD1 mRNA and protein expression (Fig. 4). In our previous study, CA diet significantly decreased the ratio of $\mathrm{C} 18: 1 / \mathrm{C} 18: 0$ fatty acids in adipose tissue and down-regulated the hepatic liver-type fatty acid-binding protein, SCD1 and fatty acid synthases mRNA expression in C57BL/6J-ob/ob mice. ${ }^{31}$ These results indicate that CA down-regulates lipogenesis by blocking the SCD pathways. Previous studies have demonstrated that decreased SCD1 expression was related to reduction of weight gain and improvement of insulin sensitivity. ${ }^{32}$

Taken together, the diverse effects of CA on adipocyte lipid accumulation are associated with adipocyte-related gene expression as well as fatty acid composition (Fig. 5). These changes could lead to improvements in insulin resistance and abnormal glucose control induced by obesity, although further in vivo studies are needed to confirm this relationship.

\section{ACKNOWLEDGMENTS}

This research was supported by the SRC program (Center for 
Food \& Nutritional Genomics: grant number 2012-0000642) and the Mid-Career Research Program (2012R1A2A2A01046228) of the National Research Foundation (NRF) of Korea, funded by the Ministry of Education, Science, and Technology.

\section{CONFLICTS OF INTEREST}

No potential conflicts of interest were disclosed.

\section{REFERENCES}

1. Otto TC, Lane MD. Adipose development: from stem cell to adipocyte. Crit Rev Biochem Mol Biol 2005;40:229-42.

2. Tan CY, Vidal-Puig A. Adipose tissue expandability: the metabolic problems of obesity may arise from the inability to become more obese. Biochem Soc Trans 2008;36:935-40.

3. Virtue S, Vidal-Puig A. It's not how fat you are, it's what you do with it that counts. PLoS Biol 2008;6:e237.

4. Rosen ED, MacDougald OA. Adipocyte differentiation from the inside out. Nat Rev Mol Cell Biol 2006;7:885-96.

5. Hulver MW, Berggren JR, Carper MJ, Miyazaki M, Ntambi JM, Hoffman EP, et al. Elevated stearoyl-CoA desaturase-1 expression in skeletal muscle contributes to abnormal fatty acid partitioning in obese humans. Cell Metab 2005;2:251-61.

6. Hyun CK, Kim ED, Flowers MT, Liu X, Kim E, Strable M, et al. Adipose-specific deletion of stearoyl-CoA desaturase 1 up-regulates the glucose transporter GLUT1 in adipose tissue. Biochem Biophys Res Commun 2010;399:480-6.

7. Sjögren P, Sierra-Johnson J, Gertow K, Rosell M, Vessby B, de Faire $\mathrm{U}$, et al. Fatty acid desaturases in human adipose tissue: relationships between gene expression, desaturation indexes and insulin resistance. Diabetologia 2008:51:328-35.

8. Roberts R, Hodson L, Dennis AL, Neville MJ, Humphreys SM, Harnden KE, et al. Markers of de novo lipogenesis in adipose tissue: associations with small adipocytes and insulin sensitivity in humans. Diabetologia 2009;52:882-90.

9. Wang T, Takikawa Y, Satoh T, Yoshioka Y, Kosaka K, Tatemichi Y, et al. Carnosic acid prevents obesity and hepatic steatosis in ob/ob mice. Hepatol Res 2011;41:87-92.

10. Park MY, Mun ST. Dietary carnosic acid suppresses hepatic steatosis formation via regulation of hepatic fatty acid metabolism in high-fat diet-fed mice. Nutr Res Pract 2013;7:294-301.

11. Livak KJ, Schmittgen TD. Analysis of relative gene expression data using real-time quantitative PCR and the 2(-Delta Delta C(T)) Method. Methods 2001;25:402-8.

12. He ML, Hnin TM, Kuwayama H, Mir PS, Okine EK, Hidari H. Effect of conjugated linoleic acid type, treatment period, and dosage on differentiation of 3 T3 cells. Lipids 2006;41:937-49.

13. Kramer JK, Fellner V, Dugan ME, Sauer FD, Mossoba MM, Yurawecz MP. Evaluating acid and base catalysts in the methylation of milk and rumen fatty acids with special emphasis on conjugated dienes and total trans fatty acids. Lipids 1997:32:1219-28.

14. Romo-Vaquero M, Selma MV, Larrosa M, Obiol M, García-Villalba $\mathrm{R}$, González-Barrio R, et al. A rosemary extract rich in carnosic acid selectively modulates caecum microbiota and inhibits $\beta$-glucosidase activity, altering fiber and short chain fatty acids fecal excretion in lean and obese female rats. PLoS One 2014;9: e94687.

15. Kim YJ, Kim JS, Seo YR, Park JH, Choi MS, Sung MK. Carnosic acid suppresses colon tumor formation in association with antiadipogenic activity. Mol Nutr Food Res 2014:58:2274-85.

16. Shin HB, Choi MS, Ryu B, Lee NR, Kim HI, Choi HE, et al. Antiviral activity of carnosic acid against respiratory syncytial virus. Virol J 2013;10:303.

17. Raes K, Doolaege EH, Deman S, Vossen E, De Smet S. Effect of carnosic acid, quercetin and a-tocopherol on lipid and protein oxidation in an in vitro simulated gastric digestion model. Int J Food Sci Nutr 2015:1-6.

18. Harach T, Aprikian O, Monnard I, Moulin J, Membrez M, Béolor JC, et al. Rosemary (Rosmarinus officinalis L.) leaf extract limits weight gain and liver steatosis in mice fed a high-fat diet. Planta Med 2010;76:566-71.

19. Romo Vaquero M, Yáñez-Gascón MJ, García Villalba R, Larrosa M, Fromentin E, Ibarra A, et al. Inhibition of gastric lipase as a mechanism for body weight and plasma lipids reduction in Zucker rats fed a rosemary extract rich in carnosic acid. PLoS One 2012; 7:e39773.

20. Takahashi T, Tabuchi T, Tamaki Y, Kosaka K, Takikawa Y, Satoh T. Carnosic acid and carnosol inhibit adipocyte differentiation in mouse 3T3-L1 cells through induction of phase2 enzymes and activation of glutathione metabolism. Biochem Biophys Res Commun 2009;382:549-54.

21. Ou X, Ji C, Han X, Zhao X, Li X, Mao Y, et al. Crystal structures of human glycerol 3-phosphate dehydrogenase 1 (GPD1). J Mol Biol 2006:357:858-69.

22. Rosen ED, Walkey CJ, Puigserver P, Spiegelman BM. Transcriptional regulation of adipogenesis. Genes Dev 2000;14:1293-307.

23. Lefterova MI, Zhang Y, Steger DJ, Schupp M, Schug J, Cristancho A, et al. PPARgamma and C/EBP factors orchestrate adipocyte biology via adjacent binding on a genome-wide scale. Genes Dev 2008:22:2941-52.

24. Gaya M, Repetto V, Toneatto J, Anesini C, Piwien-Pilipuk G, Moreno S. Antiadipogenic effect of carnosic acid, a natural compound present in Rosmarinus officinalis, is exerted through the C/EBPs and PPARg pathways at the onset of the differentiation program. Biochim Biophys Acta 2013;1830:3796-806.

25. Wang T, Takikawa Y, Tabuchi T, Satoh T, Kosaka K, Suzuki K. Carnosic acid (CA) prevents lipid accumulation in hepatocytes through the EGFR/MAPK pathway. J Gastroenterol 2012;47:805-13.

26. Park MY, Mun ST. Carnosic acid inhibits TLR4-MyD88 signaling pathway in LPS-stimulated 3T3-L1 adipocytes. Nutr Res Pract 2014:8:516-20.

27. Matsubara Y, Kano K, Kondo D, Mugishima H, Matsumoto T. Differences in adipocytokines and fatty acid composition between two adipocyte fractions of small and large cells in high-fat diet-induced obese mice. Ann Nutr Metab 2009:54:258-67.

28. Voss MD, Zoller G, Matter H, Herling AW, Biemer-Daub G, Pfenninger A, et al. Discovery and pharmacological characterization of SAR707 as novel and selective small molecule inhibitor of stearoyl-CoA desaturase (SCD1). Eur J Pharmacol 2013;707: 140-6.

29. García-Serrano S, Moreno-Santos I, Garrido-Sánchez L, GutierrezRepiso C, García-Almeida JM, García-Arnés J, et al. Stearoyl-CoA desaturase- 1 is associated with insulin resistance in morbidly obese subjects. Mol Med 2011;17:273-80. 
30. Vinknes KJ, Elshorbagy AK, Drevon CA, Nurk E, Tell GS, Nygård $O$, et al. Associations between plasma polyunsaturated fatty acids, plasma stearoyl-CoA desaturase indices and body fat. Obesity (Silver Spring) 2013;21:E512-9.

31. Park MY, Sung MK. Carnosic acid attenuates obesity-induced glucose intolerance and hepatic fat accumulation by modulating genes of lipid metabolism in C57BL/6J-ob/ob mice. J Sci Food Agric 2015:95:828-35.

32. Poudyal H, Brown L. Stearoyl-CoA desaturase: a vital checkpoint in the development and progression of obesity. Endocr Metab Immune Disord Drug Targets 2011;11:217-31. 